\title{
Bullying e Processos de Escolarização: Diálogos e Perspectivas Pedagógicas
}

\section{Bullying and the Schooling Processes: Dialogues and Pedagogical Perspetices}

\author{
Vanessa Costa Gonçalves Silva ${ }^{\mathrm{a}}$ R Raquel Martins Fernandes Mota*a; Maria das Graças Campos ${ }^{\mathrm{b}}$ \\ aInstituto Federal de Educação, Ciência e Tecnologia de Mato Grosso, Programa de Pós-Graduação Stricto Sensu em Ensino. MT, Brasil. \\ 'Universidade de Cuiabá, Programa de Pós-Graduação Stricto Sensu em Ensino. MT, Brasil. \\ *E-mail: raquel.fernandes@blv.ifmt.edu.br \\ Recebido em: 15/02/19; Aceito em: 26/06/19
}

\begin{abstract}
Resumo
Os processos de escolarização são marcados por etapas diversas de um desenvolvimento psicossocial, alguns fatos e intervenções podem interferir neste processo significativamente, dentre estes se destaca a violência escolar, como forte elemento que despotencializa os resultados. Como intervir pedagogicamente de modo a prevenir, combater e tratar o bullying é uma das questões levantadas pelo grupo de pesquisa em Humanidades e Sociedade Contemporânea do IFMT e aqui elencada, com o objetivo de perceber as subjetividades no processo e como atuar na perspectiva pedagógica em relação a mesma. Foram pesquisadas sete escolas, entre 2016 e 2018, com questionário diagnóstico sobre bullying e violação dos Direitos Humanos. Apresentam-se alguns resultados da pesquisa e intervenções realizadas, bem como revisão de literatura sobre a atuação pedagógica. Dos 616 estudantes, 121 afirmaram ter sofrido violação de seus direitos no ambiente escolar (21,3\%); os mesmos sugeriram várias atividades para combater o bullying, das quais algumas foram realizadas de modo satisfatório. Percebe-se que ao trabalhar no Ensino Médio, o protagonismo jovem é o elemento principal para atuar em prol da preservação dos direitos humanos de um modo geral.
\end{abstract}

Palavras-chave: Ensino. Violência Escolar. Direitos Humanos. Currículo.

\begin{abstract}
The schooling processes are marked by different psychosocial development stages, some facts and interventions can significantly interfere in this process, among them the school violence stands out as a strong element that deprives the results. How to interfere pedagogically in order to prevent, combat and treat bullying, is one of the questions raised by the research group on Humanities and Contemporary Society of IFMT and here listed, having as an aim of perceiving the subjectivities in the process and how to act in the pedagogical perspective in relation to it. Seven schools were surveyed, between 2016 and 2018, with a diagnostic questionnaire on bullying and human rights violations. Some results of the research and interventions carried out are exhibited, as well as a literature review about the pedagogical performance. From 616 students that answered the questionnaire, 121 reported having suffered a violation of their rights in the school environment (21.3\%); they suggested several activities to combat bullying, which ones were carried out satisfactorily. It is noticed that when it is worked in high school, the young protagonism is the main element to act for the human rights preservation in general.
\end{abstract}

Keywords: Teaching. School Violence.Human Rights.Curriculum

\section{Introdução}

Violência, discriminação, preconceito, xenofobia, direitos humanos, ensino de filosofia, bullying, ciberbullying, educação ambiental, ciência e tecnologia são alguns dos temas abordados nas atividades de ensino-pesquisa e extensão do Grupo de Pesquisa em Humanidades e Sociedade Contemporânea - GPHSC do IFMT, além de discussões sobre temas como estes, o Grupo busca suscitar ações que combatam as mazelas que assolam a sociedade.

Criado no ano de 2008, por professores da área de filosofia com o objetivo de compreender a dinâmica do momento contemporâneo, atualmente, conta com uma equipe multidisciplinar e atua com uma metodologia de pesquisa transdisciplinar, produzindo diferentes recortes de um mesmo sujeito pesquisado, buscando encontrar, na diversidade de experiências e visões teóricas e seus pesquisadores, os conceitos e os métodos adequados a uma compreensão interdisciplinar desse objeto.

No ano de 2016, o Grupo de Pesquisa deu início a uma pesquisa intitulada Violação dos Direitos Humanos e Bullying no Contexto Escolar: Diagnóstico e Proposta de Intervenção com Base no Empoderamento dos Alunos, foram pesquisadas sete instituições de ensino, sendo estas, duas escolas da rede estadual, uma escola da rede particular e quatro campi do IFMT, sendo entrevistado o total de 616 estudantes. Nesse sentido são apresentados os resultados gerais desta pesquisa e as contribuições específicas de atividades de intervenção pedagógicas realizadas no IFMT, campus Cuiabá Bela Vista, com intuito de refletir sobre o processo de aprendizagem e ensino no contexto de violência escolar e violação dos Direitos Humanos, na perspectiva das subjetividades e singularidades inerentes.

Zabala (2002) faz uma exposição geral sobre os diversos métodos globalizadores. $\mathrm{O}$ autor mostra as mais recentes tendências pedagógicas, as quais nomeiam métodos 
globalizadores: Centros de Interesse, Método de projetos, Investigação do meio, Projetos de trabalho global. O autor mostra que o diferencial de uma intervenção pedagógica pode ser o papel que os conteúdos têm frente às necessidades sociais. Um conteúdo é proposto, em um currículo, não pela sua importância, mas pela necessidade de responder algo. Essa necessidade não é definida de forma unilateral, nem conforme interesses e circunstâncias, embora esses precisem ser levados em conta e ser utilizados como ponto de motivação à investigação.

Desse modo, frente às situações vivenciadas, no contexto escolar, cabe ao educador encontrar uma perspectiva pedagógica que permita lidar com os problemas sociais, de forma interdisciplinar; o que vem ao caso na necessidade social de combater a violência escolar.

Observa-se, então, que para evitar o senso comum e também a reprodução apática de conceitos é preciso que a sequência didática, em sala de aula, siga o interesse da comunidade (nem só dos estudantes, nem só do professor) e, ao mesmo tempo, o objeto e problemas próprios da disciplina proposta. Segundo Zabala (2002), o enfoque globalizador na educação pretende retomar como objeto de estudo a própria realidade; as disciplinas curriculares para responder um problema real. Nesse sentido, o autor enfatiza o ensino a partir de problemas reais; não sendo as disciplinas e seus conteúdos o objeto de estudo. Um enfoque globalizador permite ao educador, por exemplo, debater problemas reais vivenciados pelos estudantes em seu cotidiano escolar, em uma transversalidade dos temas, em que os conteúdos disciplinares surgem como elementos, que permitem o aprofundamento ao problema.

A visão de uma prática pedagógica voltada para formação integral, proposta por Zabala (1998), é um fundamento que articula a compreensão macro de que o processo de ensinoaprendizagem é uma prática social complexa. Assim, conforme Marin e Pimenta (2018), é uma prática realizada por seres humanos, entre seres humanos, que são transformados pela ação e relação entre os sujeitos, situados em contextos diversos: institucionais, culturais, teoria e pesquisa espaciais, temporais e sociais, que tornam esse processo mais complexo e significativo em função da necessidade de considerar as subjetividades do ser humano e seus contextos.

Outra perspectiva pedagógica, que pode ser trazida ao debate, diz respeito às dimensões do currículo e suas relações com o conceito de conteúdo, em que este conceito contemple os processos de desenvolvimento e de socialização dos seres humanos, o que é preconizado por Coll et al. (2000). Os autores sugerem a reformulação que rompa com a estrutura tradicional, em que o currículo se refere apenas a conteúdos conceituais levados de forma transmissiva e cumulativa. E permite pensar a relação dos conteúdos com o próprio processo de desenvolvimento e de socialização. Nesse sentido, a reforma contempla outros tipos de conteúdo, tais como: os procedimentos e as atitudes, valores e normas (COLL, 2000).
Assim, o currículo seria organizado em três eixos: saber, saber fazer e avaliar; respectivamente correspondem aos conteúdos conceitual, procedimental e atitudinal, em que conteúdo e método seriam canalizados em um único processo de aquisição de conhecimentos, de habilidades e de atitudes cognitivas e sociais. Essa mesma perspectiva epistemológica e didática pode ser pensada no currículo de uma disciplina específica, na qual a ênfase no conteúdo é sustentada e o procedimento transmissivo rejeitado; e as dimensões do conteúdo deixam de ser simplesmente conceituais e passam a denotar as dimensões do fazer e do agir, elementos axiológicos e sociais de uma formação ética, estética e política.

A subjetividade e a objetividade nas relações pedagógicas dizem respeito a dois tipos de relações básicas, as dos indivíduos entre si, nas quais os sujeitos se tornam objetos de si mesmos e enquanto sujeitos vivem um processo interpessoal, que será quão mais intersubjetivo, quanto mais objetivas forem as relações sociais. Portanto, neste caso, as relações sociais pressupõem uma postura ética de aceitação do outro e uma postura política que visa tomada de decisões em comum; a intersubjetividade se consumou na objetividade (em termos de alcançar o fim social desejado). Em resumo: o conhecimento é produzido na relação interpessoal e é daí que seu caráter epistemológico-metodológico, a intersubjetividade pressupõe um viés ético-político.

Do ponto de vista psicológico, um dado subjetivo pode influir nas relações pedagógicas, obstruindo ou favorecendo a produção de significado e de sentido. As relações pedagógicas dentro do ponto de vista epistemológico-metodológico deveriam permitir, instigar e propiciar a produção de conhecimento nessa relação sujeito-objeto.

Contudo, não há só o aspecto epistemológicometodológico, que influi na produção de conhecimentos em relações pedagógicas. Na perspectiva da psicologia existem várias relações que influem nos processos cognitivos em geral, determinados pelo nível de abordagem do discurso, tais como: o nível intrapessoal, interpessoal e interinstitucional (COLL; EDWARDS, 1998). A subjetividade e a aproximação à objetividade ocorrem em diferentes níveis do discurso, podendo ou não produzir relações de intersubjetividade. No nível do discurso institucional, por exemplo, a cristalização de normas e leis pode inviabilizar, através da pretensiosa objetividade, a intersubjetividade.

Do ponto de vista intrapessoal, vários são os fatores que influem no processo de ensino e aprendizagem: inteligências, aptidões, personalidade, motivação e estratégias de aprendizagem; a estrutura psíquica do sujeito também influi, nas relações intersubjetivas e pode, se não forem usadas estratégias condizentes, prejudicar ou diminuir a produção de significados no processo de aprendizagem. Contudo, no nível interpessoal, vários fatores sociais e ambientais vão influir na produção efetiva de conhecimentos: 1- cenário educativo, 2comportamento do professor, 3- estilo de ensino, 4- dimensões 
de ação didática, 5- representação mútua da relação professor/ aluno, 6- interação entre professor/aluno e 7-interação entre os alunos (COLL, 1996).

A concepção da intersubjetividade demanda um olhar aprofundado para as questões humanísticas e da plenitude do sujeito, que Zabala (2002) considera necessário perceber que as aprendizagens dependem das características singulares de cada um dos aprendizes. Daí decorre que um enfoque pedagógico deve observar e dar atenção à diversidade dos estudantes como eixo estruturante, que o mesmo tem um papel ativo e de protagonismo em seu processo de ensinoaprendizagem. Frente a esta perspectiva de uma aprendizagem em que o estudante se torna protagonista e sujeito atuante em sua formação, cita-se Zabala (2002), que traz como papel da escola dar ao estudante o seu verdadeiro lugar de ensino, o enfoque globalizador como instrumento de ajuda para a aprendizagem e o desenvolvimento dos estudantes, não supõe a rejeição das disciplinas e dos conteúdos escolares, mas extrapolar os limites do conhecimento livresco, enciclopédico. Implica em um currículo estruturado de forma flexível e dinâmica, que atenda a demanda dos sujeitos escolares.

Entre estas demandas se encontra a violência escolar, e mais especificamente, o bullying. O termo bullying ultimamente tem sido usado para relacionar todo ato de intimidação sistemática ocorrida entre pares em ambientes sociais, como: escola, clube, trabalho e, até mesmo, na família. Embora não seja um fenômeno novo, pois é do conhecimento comum, que sempre existiu dentro da escola, o termo pertence à língua inglesa, passou a ser usado no Brasil, recentemente, e tem sido objeto de estudos acadêmicos. O vocábulo só se tornou conhecido no Brasil por conta dos estudos acadêmicos iniciados, nos Estados Unidos, nos anos 1970 (OLIVEIRA et al., 2017).

A Lei $n^{\circ} 13.185$, de 6 de dezembro de 2015, institui o Programa de Combate à Intimidação Sistemática (bullying) no Brasil, foi criada com o objetivo de manter uma cultura de paz dentro das escolas. Daí emerge as proposituras do presente texto, dos diálogos pedagógicos possíveis, em um contexto escolar adverso, e como transformar este contexto, favorecendo relações interpessoais saudáveis e um ambiente propício ao conhecimento em todas suas dimensões.

\section{Material e Métodos}

A metodologia de pesquisa é qualitativa na perspectiva da pesquisa bibliográfica e da observação assistemática das atividades pedagógicas, enquanto educadores, bem como resultados de pesquisa qualitativa realizada pelo grupo de pesquisa.

Através de revisão de literatura foi possível selecionar e estabelecer um diálogo entre autores, que abordam um ensino globalizador e as questões que permeiam a violência escolar e a violação dos Direitos Humanos, tais como: Zabala (2002, 1998), César Coll (2000, 1998, 1996), Marin e Pimenta (2018), Tomás Tadeu Silva (2015), Certeau (2004), Clemildo
Anacleto da Silva (2009).

Utilizou-se, também, para compor este trabalho, os resultados do grupo de pesquisa. O grupo mapeou, inicialmente, através de questionário online disponibilizado pelo googledrive, (composto por 24 questões fechadas e duas questões abertas) aos estudantes participantes, que tiveram a opção de responder em diversos espaços (casa, escola, smartphone), o mesmo foi aplicado a 616 estudantes do Ensino Médio, de sete escolas no Estado de Mato Grosso.

Posteriormente, foram realizadas entrevistas nas diversas escolas, das quais neste texto são resgatadas as contribuições de dois integrantes da equipe multiprofissional (psicólogo e assistente social) de uma das escolas pesquisadas. No retorno a campo, também houve atividades de intervenção pedagógica, tais como: festival de vídeo, poema, música, palestras, mesasredondas, roda de conversas, entre outras.

\section{Resultados e Discussão}

\subsection{Apresentação inicial dos resultados da pesquisa}

$\mathrm{Na}$ pesquisa desenvolvida pelo GPHSC-IFMT com alunos do Ensino Médio foi disponibilizado questionário online, através de formulário do google-drive, do total de 616 alunos, que responderam aos questionários, 121 afirmaram ter sofrido violação de seus direitos no ambiente escolar $(21,3 \%)$; entre estes, o percentual maior se encontra na escola particular $(51,85 \%)$, e o número maior de vítimas são do sexo masculino (53,57\%). Entre as agressões, as que atingem um maior percentual: apelidos (48\%) e insultos em função de características físicas $(48 \%)$, - dizer coisas negativas sobre a pessoa ou família (34\%), sendo a agressão física um percentual menor (12\%). Nas sugestões dos adolescentes contra o bullying, os mesmos se colocam como protagonistas sociais, visando uma geração mais humana, e a construção de ambientes democráticos, que possibilitam o respeito às diferenças, consequentemente, inibindo e prevenindo a violência física ou simbólica.

A partir desta pesquisa foi possível perceber a necessidade de formação continuada dos professores para efetivar um trabalho transformador no que diz respeito aos temas transversais.

Nas nove formas, em que o bullying se desdobra, e a violência demonstra sua face, conforme relato das próprias profissionais de uma das instituições pesquisadas, os atendimentos são realizados, os pais são chamados, ações pontuais são feitas. Não existe um protocolo padrão de atendimento a situações de bullying, pois, segundo a Profissional 1, os casos são conversados e analisados individualmente; conforme o relato da profissional, todos têm consciência da responsabilidade da escola para prevenir e combater essa prática,

legalmente falando eu creio que já exista o suficiente, pois temos uma Lei Federal que fala da intimidação sistemática, eu acho que toda escola já é munida de informações como está inscrita em seus próprios documentos que traz a sua missão, a 
sua missão social, sua função, sua meta, os direitos, os deveres e as obrigações... precisa haver formação para os professores, pois o problema não está especificamente no que está escrito, mas principalmente pelo discurso dos profissionais que aí sim a gente pode mexer, tem professor que entra em sala de aula falando contra as cotas que escola caiu a qualidade depois que entrou alunos através de cotas automaticamente, este é um discurso que promove a desigualdade entre os alunos porque se o professor usa esse discurso e teve essa fala isso não é bullying pois se o professor disse que o aluno cotista é burro não é bullying por que quem disse isso foi o professor, o professor é cientista o professor é doutor... (Entrevista Profissional 1, 2018).

Diante de todos os fatos narrados é interessante debater a responsabilidade da escola frente a toda a problemática do bullying, já que, após a sanção da Lei $\mathrm{n}^{\circ} 13.663$, de 14 de maio de 2018, esta altera o artigo 12 da Lei no 9.394, de 1996 (Lei de Diretrizes e Bases da Educação Nacional). A lei inclui a responsabilidade da escola para promoção de medidas de combate ao bullying, que visa prevenir e combater todos os tipos de violência, a partir da promoção da cultura da paz na escola. O trecho do texto acrescenta os incisos IX e X,

Art. 12.

IX - promover medidas de conscientização, de prevenção e de combate a todos os tipos de violência, especialmente a intimidação sistemática (bullying), no âmbito das escolas;

$\mathrm{X}$ - estabelecer ações destinadas a promover a cultura de paz nas escolas.» (NR)

(BRASIL, Lei no 13.663, de 14 de maio de 2018).

Os estudantes já sinalizavam a importância de resolver a questão com ações institucionais, como segue em alguns relatos:

Trazer esse assunto para a escola, falar sobre isso para que as pessoas que fazem bullying entender que isso é sério, e pode machucar muito uma pessoa, mesmo que tenha feito ou falado alguma coisa só por brincadeira. (Estudante, 17 anos). $\mathrm{O}$ assunto deve ser amplamente discutido através de palestras e rodas de conversas, e também criar um mecanismo em que o aluno possa falar o bullying que sofreu e se sinta seguro fazendo isso. (Estudante, 16 anos).

Discutir abertamente com palestras/ou por meio de professores sobre raça, ideologia de gênero, orientação sexual, saúde e etc. discutir abertamente com argumentos que não sejam PRECONCEITUOSOS e CONSERVADORES. (Estudante, 15 anos).

Há um entendimento dos estudantes que está preconizado na Lei Antibullying, que a escola e seus profissionais devem estar aptos para o enfrentamento dessa problemática, a partir do reconhecimento de que a escola não pode ser omissa, negando a existência do bullying e da violência.

\subsection{Atividades de intervenção pedagógica nas relações de tolerância e intolerância}

Certeau (2004) traz o conceito de mecanismos de resistência, que é uma forma dos mais fracos usarem de sua inventividade para inverter a lógica do dominante, no caso do bullying a vítima se empoderar em uma espécie de neutralização às investidas do agressor.

Esse processo de reinventar o seu cotidiano e driblar as mazelas do bullying pode ocorrer mediante o empoderamento das vítimas, que conseguem buscar forças e apoio em uma rede estabelecida dentro do espaço escolar. Sendo uma forma de não ceder às violações sofridas e se empoderar por intermédio do protagonismo jovem, que é uma estratégia de fortalecimento e empoderamento das minorias, que se unem para combater o que fere sua integridade física, psíquica e emocional.

Este protagonismo jovem é algo a ser estabelecido na construção da identidade do próprio adolescente, por meio do autoconhecimento, do desenvolvimento da autoestima e do fortalecimento de suas ações e da ação educativa proposta pela instituição de ensino.

O protagonismo jovem é uma forma de tática de praticantes (CERTEAU, 2004, p. 45), em que os chamados fracos se opõem à lógica dos chamados fortes. Essas táticas criam uma microrresistência, que visa fortalecimento do sujeito, fazendo com que o mesmo seja protagonista de sua história, garantindo seu espaço no cotidiano, rompendo com modelos preestabelecidos e com a banalização do mal, que ainda é presente no cotidiano escolar.

Conforme Costa (2000), o protagonismo parte de ação educativa, como a criação de espaços e condições capazes de possibilitar aos jovens se envolverem em atividades direcionadas à solução de problemas reais, atuando como fonte de iniciativa, liberdade e compromisso. O "ser" protagonista é ser capaz de se colocar como sujeito construtor de seus projetos de vida e de se ver como elemento, que contribui para a solução dos desafios individuais e coletivos.

A partir das respostas do questionário online à pergunta aberta: "O que você sugere que seja feito para acabar com o bullying?", seguem algumas que mostram a percepção dos estudantes quanto à promoção de diálogos na escola para combater o bullying.

Contribuição 01:

Conscientização dos estudantes sobre as diferenças que cada pessoa tem em particular seja de gênero, opção sexual, religião, cor, entre outras. Também é preciso incentivar que quem sofra bullying conte o ocorrido para uma pessoa adulta, os pais ou a pessoa responsável na escola para tomar alguma providência, para isso é necessário que os pedagogos e coordenadores das escolas e principalmente os pais conquistem a confiança dessa criança ou jovem para contar o que acontece de negativo com ele na escola. (Estudante, 18 anos).

Contribuição 02:

Palestras, fiscalização e punições. (Estudante, 17 anos). Contribuição 03:

Talvez se esse assunto fosse mais falado através de aulas, atividades escolares e palestras tanto no Ensino Fundamental, quanto no Médio, haveria uma diminuição. Também acredito que educação vem de casa sim! Se os pais alertarem seus filhos de que isso não é legal, esse estudante vai passar a ter consciência de que isso está incomodando ao seu próximo. Muitos jovens afetados acabam se fechando para o mundo, se tornando pessoas tímidas com a autoestima baixa por culpa do bullying que sofre. (Estudante, 15 anos).

Contribuição 04:

Acredito que deve haver uma grande demanda por parte dos professores e funcionários em propagar o perigo do bullying e 
punir severamente aqueles que o praticam tornando miserável a vida de outro colega. Poucos estudantes que sofrem bullying e poucos colegas que presenciam denunciam o ato, por medo de sofrerem o mesmo (ganhando apelidos ou sendo vítimas de brincadeiras de mal gosto) ou indiferença, por aquilo não ser da sua conta. Mas temos que começar a nos preocupar com aqueles que por um motivo ou outro (um comentário, ou uma piada), mesmo que não dirigidos diretamente, se sentiram ofendidos e tiveram sua saúde mental abalada. Grande parte dos estudantes do campus em que estudo são adolescentes em fase de formação de opinião e orientação sexual variada ou indefinida. Temos religiões diferentes, etnias diferentes, costumes diferentes, sexos diferentes e, enfim, diferentes modos de agir e pensar e ninguém, em momento nenhum, deve se sentir ofendido, ameaçado ou culpado por ter uma personalidade ou opinião diferente da dos demais (desde que não interfira no direito de expressão e liberdade alheio). (Estudante, 16 anos).

Pode-se perceber que as sugestões dos estudantes para acabar com o bullying na escola são as mais variadas. $\mathrm{Na}$ fala dos estudantes, a escola foi colocada como o local de suma importância para o enfrentamento; segundo eles, os profissionais devem ser capacitados para atendimento ao sujeito que sofre ou pratica o bullying, além de serem os responsáveis para promover ações para abordar esse tema.

A escola sendo esse espaço de resistência e de protagonismo pode proporcionar a construção de um espaço que transforme, a partir do reconhecimento de que os sujeitos pertencentes a esse cotidiano precisam ser respeitados por suas diferenças e que, a partir de uma rede de ações, pode promover debates sobre as questões pertinentes e inquietantes a esses sujeitos praticantes do cotidiano escolar; algumas ações foram evidenciadas e apresentaram avanços na luta pela melhoria do clima escolar e no combate a ações de violação de direitos e do bullying. Essas percepções de que podem, sim, por meio do empoderamento criar um espaço de escritas e de reescritas, que são rupturas com modelos existentes e impostos de cima para baixo.

Projetos pedagógicos e atividades curriculares são ferramentas para debates, que visam ações e melhoria para o espaço escolar, como eventos voltados para os direitos humanos e cidadania, diversidade e respeito. Ouvir os estudantes sinaliza a vontade de mudar e ter ideias que sejam aplicáveis e significativas, pois quando se envolvem há interesse:

Trabalhar com esses estudantes em várias vertentes onde eles possam dar ideias de eventos e de atividades de aulas, onde alguns deram ideias de cartazes de eventos tema de redação ou de competição não sei, mas algo que venha deles. Isso deve ser algo contínuo, uma política permanente de combate ao bullying, ele precisa estar instituído na cultura organizacional e que fazemos com que os estudantes participem. (Entrevista Profissional 1, 2018).

Conforme Certeau (2004, p.203) pondera, os relatos efetuam um trabalho incessante, "transforma lugares em espaços e espaços em lugares", pois, segundo o autor, o espaço é um lugar praticado; esse movimento organiza os jogos das relações mutáveis que uns mantêm com os outros.
Por esse entendimento se percebe que as relações mutáveis proporcionam mudanças de atitudes e comportamentos entre os sujeitos e o espaço, podendo promover a mudança de conceitos e de paradigmas, que torne um espaço hostil em um lugar salutar e benéfico aos seus praticantes.

Certeau (2004, p.202) ainda traz a concepção de espaço como um "conjunto de movimentos que aí se desdobram", que pode ser modificado pelas transformações que ocorrem em função de proximidades sucessivas. Essa aproximação promove a experiência do reconhecimento do "eu" e do reconhecimento do "outro". Por esse motivo é fundamental que a escola promova atividades de aproximação e de acolhimento entre os estudantes, que podem criar vínculos e compreender a concepção do que "existir no mundo" que é composto por vários outros "mundos".

$\mathrm{Na}$ arte de fazer, de reinventar o espaço, de subverter a lógica imposta e de criar táticas de praticantes é que surgem ações pautadas no protagonismo dos estudantes. A arte, o esporte e a cultura podem ser elementos fundamentais para explicitar as visões de mundo, os valores; e serem usados como uma forma prática de aprendizagem e de desenvolvimento da resiliência. Melhorando a sua percepção do grupo, sua autoestima e de pertencimento ao espaço. Segue relato de algumas ações, que emergiram da demanda dos estudantes.

Figura 1 - Foto da Instalação Artística GPHSC - Sábado Letivo - Setembro amarelo

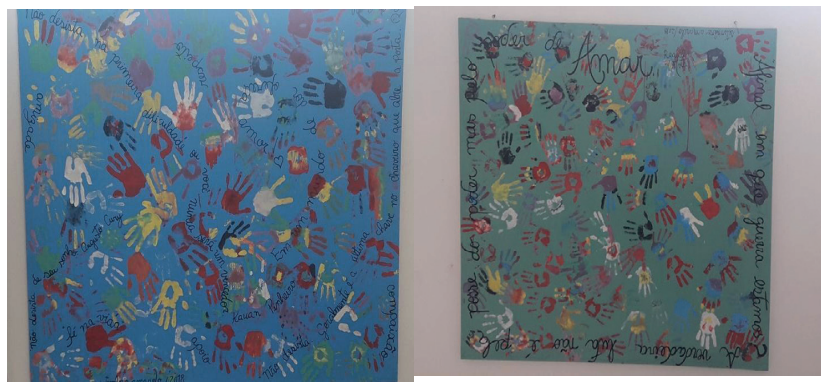

Fonte: Os autores.

No evento retratado houve palestras diversas e, durante o intervalo das mesmas, o GPHSC, a partir de sugestões de seus membros, inclusive dos estudantes integrantes do grupo, promoveu uma instalação artística na cantina do campus, na qual os estudantes puderam, em um registro simbólico, deixar sua marca; cada mão trouxe a sua história de vida e registrou no painel, que está exposto na escola, com diversas mensagens de sensibilização, nas quais o enfoque principal foi que todos são importantes, singulares e diversos. 
Figura 2 - Foto do Varal poético - Semana Cívica

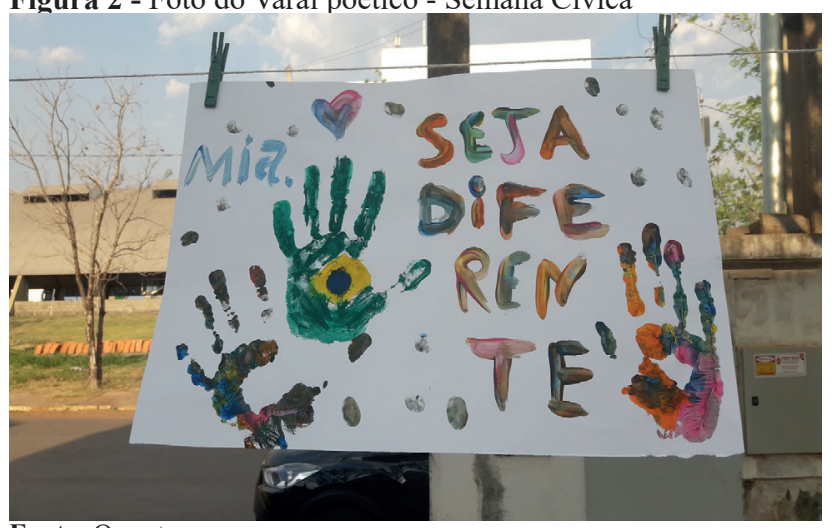

Fonte: Os autores.

Os estudantes puderam deixar suas mensagens, em forma de desenhos e poemas, para os demais sujeitos passantes nesse cotidiano, em que o respeito à diversidade, diferença e sensibilização à humanidade de todos ficaram evidenciados no resultado apresentado.

A escola também promoveu a Olimpíada BLV - saúde, esporte e cultura: corpo e mente em movimento, com a visão de desenvolver uma maior integração da comunidade educacional, por meio da integração de atividades esportivas e culturais em diversas modalidades com ações pautadas na participação efetiva, no respeito mútuo e moral, com foco no desenvolvimento educativo global dos estudantes. Para esse evento, os estudantes concluintes foram organizadores da programação e responsáveis pela realização de cada modalidade esportiva, cultural e artística, que iniciou com apresentação de dança dos grupos com a temática "a luta das minorias".

Outro evento que ocorreu foi o projeto Curta BLV, que reuniu estudantes dos cursos de Ensino Médio Integrado, Técnico Subsequente e estudantes de outros Campi. Esse evento proporcionou, aos estudantes, oficinas de cinema, música e poesia, exibição de filme e debate sobre o tema do bullying, em que puderam conhecer ou aprimorar técnicas para subsidiar suas produções.

Figura 3 - Cartazes de divulgação do V CURTABLV / GPHSC
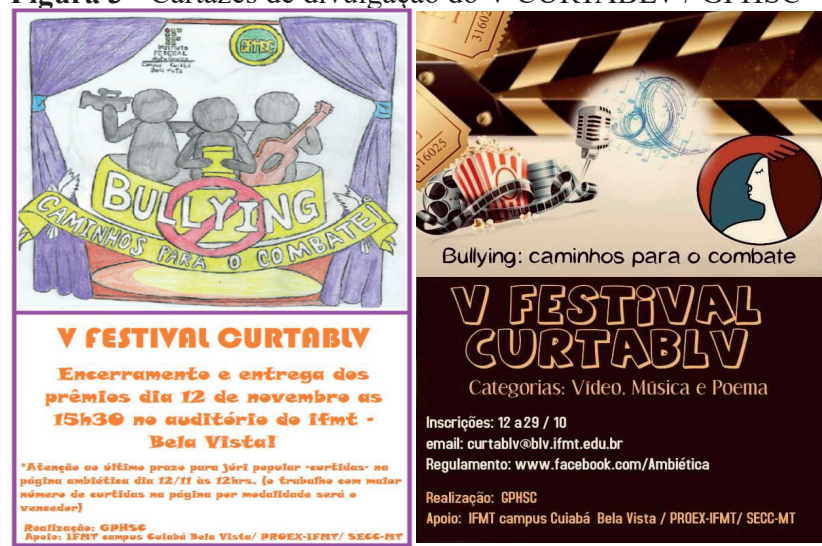

Fonte: Os autores

O evento proposto pelo GPHSC aos estudantes gerou trabalhos, que foram divulgados em redes sociais e plataformas de vídeos, o que culminou em propostas de enfrentamento ao bullying. O Festival CurtaBLV é um trabalho multidisciplinar e integrado entre várias áreas do conhecimento, que em 2018 está na sua quinta edição; e cujo tema Bullying: caminhos para o combate foi sugestão dos próprios estudantes do GPHSC. O evento oportunizou aos estudantes vivências de oficinas de vídeo, poesia e música, para que pudessem criar estratégias de combate ao bullying, por meio de diversas formas de arte; o qual obteve 47 inscritos nas diversas modalidades do Festival. Sendo os estudantes premiados pelas produções, que estão disponíveis a toda comunidade em redes sociais.

As ações realizadas promoveram o fortalecimento da identidade do estudante e melhoraram o seu entorno e seu espaço de convivência, que se estabelece com respeito e tolerância. O pensar em propostas de enfrentamento, de combate, de se posicionar, de protagonismo, implica em mudança de atitude e na arte de reinventar (CERTEAU, 2004), a escola é o cenário e o cotidiano é o lugar. Há muito que se considerar da prática e do cotidiano para implementação de um currículo comprometido com a "diversidade cultural e que seja capaz de desenvolver habilidades de pensamento" (LOPES; MACEDO, 2011, p. 143).

\subsection{Das proposituras curriculares para enfrentamento da violência escolar}

O entendimento de que o currículo extrapola a especificação e a seleção de conteúdos, objetivos, metodologias e avaliações que podem ser precisamente medidos, remetem a uma concepção mais ampla e complexa sobre esta temática, que parte da premissa de que a formação humana plena do sujeito é cultural e socialmente produzida em uma conexão entre saber, identidade e poder (SILVA, 2015, p.16). A compreensão destas dimensões na formação humana esclarece as relações intersubjetivas, que permeiam o fenômeno da violência escolar, e elucidam como prevenir e combater o bullying.

Essa formação perpassa pelo desenvolvimento de saberes, que são construídos e reconstruídos pelo sujeito, que permite que esse relacione essas aprendizagens com suas necessidades cotidianas. E esse currículo pressupõe saber lidar com a subjetividade dos estudantes, sua prática de vida e sua percepção de mundo, rompendo com a concepção de uma escola curriculista que visa formar para homogeneidade.

A busca pela superação da concepção das atividades educativas como uma série de atividades intencionais, que respondam a propósitos e metas, excludente e reprodutora do sistema capitalista permite abrir diálogos sobre a reconstrução de um currículo livre, contextualizado e que extrapole as disciplinas.

É necessário que a ressignificação da prática pedagógica e dos conhecimentos elaborados e reelaborados na escola tenham sua premissa em fundamentar o pleno desenvolvimento humano, através de docentes engajados em ser e promover mudanças através da transversalidade e criatividade 
pedagógica, fundamentados em princípios da igualdade de direitos, do respeito às diferenças, da multiculturalidade e dos múltiplos saberes que precisam ser considerados no processo de ensino-aprendizagem, entendendo que a concepção deste currículo deve ser entendida como:

[...] lugar, espaço, território. O currículo é relação de poder. O currículo é trajetória, viagem, percurso. O currículo é autobiografia, nossa vida, curriculum vitae: no currículo se forja a identidade. O currículo é texto, discurso, documento. O currículo é documento de identidade (SILVA, 2015, p. 150).

O currículo como identidade é constituído por meio das diferenças, de forma que tanto a diferença quanto a identidade fazem parte de um mesmo processo de construção social e, nesse processo, as relações que são estabelecidas uns com os outros são mediadas pelo poder. Conflitos, tensões, contradições, preconceitos, afastamentos, agrupamentos, aproximações, entre outras formas interativas, integram ativamente a construção de um currículo voltado para a formação plena do ser humano.

Na perspectiva de Silva (2015), o currículo cunhado pela diferença deve, fundamentalmente, buscar outras linhas de fuga, outros devires, insistir nas possibilidades de arriscar espaços menos seguros, menos estáveis, que aqueles com os quais se vê construindo diretrizes e referenciais, estas mudanças de paradigmas são fundamentais para a valorização de uma formação cidadã inclusiva, plena, integral e humana.

Essa concepção de um currículo construído, a partir da realidade e não apenas na sequência de conteúdos, permite o desenvolvimento de uma relação de pertencimento entre os sujeitos, que vivenciam o cotidiano escolar. Essa flexibilização do currículo em uma perspectiva da formação plena se aporta em questões trazidas por Zabala (1998), quando considera que dentro das relações escolares, a comunicação entre os estudantes e docentes regula os processos de negociação, participação e construção que é um potencializador da autonomia dos estudantes, proporcionando que os mesmos percebam que a formação plena extrapola os limites escolares e que a relação com a sociedade e com o conhecimento se estabelecem ao longo da vida.

Essa concepção traz o entendimento de que o papel do ensino é relevante para o desenvolvimento das capacidades cognitivas, permitindo a compreensão dos conteúdos escolares, porém esse estudante não se limita apenas a esses saberes, pois há o entendimento de que, atualmente, esse sujeito demanda uma visão holística do conhecimento, que possibilite o autoconhecimento de suas potencialidades, equilíbrio emocional, o desenvolvimento do relacionamento intra e interpessoal, além da promoção da sua inserção social, sendo um grande desafio educacional, que demanda uma formação docente constante e permanente através da educação continuada, possibilitando que professores, constantemente, aprendam a aprender e revisitar suas práticas pedagógicas.

\subsection{O processo de formação continuada dos educadores nas relações de tolerância e intolerância}

O processo de formação continuada dos educadores, para dar conta das relações intersubjetivas precisa partir do cotidiano escolar. Apreende-se das observações do cotidiano escolar, que as frequentes queixas dos professores dizem respeito à verticalização das propostas de formação que, na maioria das vezes, não contemplam aspectos, tais como: tempo do professor e tempo escolar, articulação dos temas propostos com as reais necessidades educativas e com os problemas, que emergem no cenário e na vida da escola.

Nessa direção, não são contemplados os desejos dos principais envolvidos: professores, alunos, pais, gestores e todos, que compõem o coletivo da escola. Pressupõe-se ainda que falta conhecer estes sujeitos e as suas propostas para desencadear no Projeto Político Pedagógico as finalidades, os objetivos, as metodologias e o processo de avaliação da formação dos professores. Com isso, haveria mais participação e realização profissional dos envolvidos no processo de ensino e aprendizagem e, consequentemente, uma maior articulação dos saberes propostos nos objetivos dos participantes para construírem com o processo de transformação da realidade. Nesse sentido, Vásquez (1977) afirma que a práxis educativa é entendida como prática intencional, interpretativa e criadora, sendo nesse sentido transformadora.

Dessa forma, Gandin (1994) afirma que não há saída para o impasse da repetição, da mesmice e da desesperança; a não ser um claro confronto entre a prática, que a instituição vive em determinado momento e o ideal que esta mesma instituição se tenha proposto.

No contexto de uma formação continuada ativa, que dê conta dos problemas do cotidiano escolar, seria fundamental a realização de estudos, de observações, de pesquisas e de diagnósticos que antecedessem ao processo de formação. Outro fator relevante poderia ser a identificação e a busca do conhecimento dos contextos, dos fatos e dados que venham a contribuir para a melhoria da gestão escolar e da formação dos professores. Esta seria uma boa tomada de decisão que, possivelmente, poderia dirimir dúvidas e eliminar fatores advindos da visão aligeirada, espontânea, que às vezes podem ser inerentes aos processos cotidianos das escolas e da gestão particular e pública de bens e serviços. Dessa forma, Gandin (1994) afirma que não há saída para o impasse da repetição, da mesmice e da desesperança; a não ser um claro confronto entre a prática, que a instituição vive em determinado momento e o ideal que essa mesma instituição se tenha proposto.

Os professores, gestores e equipe multiprofissional precisam ser capacitados para atuar em uma perspectiva de formação dos temas da diversidade cultural e as relações de tolerância e intolerância. Silva (2009, p.135) traz o conceito de tolerância como uma forma de "aguentar o outro. Neste sentido, cada um permanece no seu lugar sem interferir na vida do outro", mas a tolerância deve ser assumida como modo 
de vida, agregando valores, contribuindo para uma sociedade mais pacífica, sem a intenção de se livrar do incômodo da presença do outro.

Grande desafio para a escola, no que diz respeito à formação de seu corpo docente e de sua equipe técnica, pois não é apenas levar temas transversais, que abarquem questões de direitos humanos, é necessário conhecimento sobre a história, as lutas, os contextos, sem senso comum e superficialidade, pois isso pode promover um movimento contrário em que, ao invés de promover aproximação, ocorre o afastamento. A profissional entrevistada narra episódio de uma tentativa de abordar temas de diversidade cultural sem a devida preparação.

Precisa ter atenção em tratar esses temas porque já tivemos aqui professores que tiveram a boa ideia de trazer esses debates para sala de aula e não conseguiu fechar este debate e criou todo um problema na escola, e depois dessa tentativa malsucedida, tivemos até alunos que saíram da escola desta mesma turma após esse trabalho com o professor, porque passou a sofrer bullying dos demais colegas era uma coisa que teve uma boa intenção, mas acabou sendo malsucedida. (Entrevista Profissional 2, 2018).

Fica evidente a necessidade de formação continuada para os professores sobre temas complexos da sociedade contemporânea, além de abarcar questões referentes à valorização do ser humano, da dignidade humana, de valores, de identidade e de diversidade cultural, pensando na transversalidade desses temas e sua aplicabilidade em todas as áreas do conhecimento.

Pensar em uma campanha revolucionária pois campanha para entregar folder isto já acontece eu acredito que toda a intenção é boa mas esta é uma ação que pode ter bons resultados mas acredito que uma coisa que seria bem efetiva é que todo o professor tivesse que tratar temas transversais dentro de sala de aula independente da matéria que ele trabalha que seja matemática cálculo, estatística, o que fosse esse professor vai ter que pegar uma vertente de uma causa de um problema social, racismo, homofobia, machismo, intolerância religiosa, inclusão... Um monte de tema e inserir na sua disciplina de alguma forma a gente precisa tratar esses temas nessas beiradas assim. (Entrevista Profissional 2, 2018).

Observando que alguns caminhos estão sendo trilhados, as redes tecidas, o contexto desvelado, porém como é possível compreender e estabelecer melhorias em uma instituição de ensino, na qual seus contextos e sujeitos mudam constantemente, considera-se que essa é uma luta que não se esgota, que envolve formação docente para uma formação mais humana, na qual não se perde de vista a humanidade dos seres passantes no cotidiano escolar. Chalita (2008) trata da conexão entre os seres, que não estão só e que são interdependentes, por esse motivo não se pode perder a compaixão, pois se a perder, perder-se a capacidade de se incomodar com o sofrimento alheio e os incomodados são capazes de mudar o mundo.

Nesse movimento de perceber esta interconexão humana, que um mal interfere no coletivo, é preciso considerar Certeau (2004), quando relata que continua havendo diferenças sociais, econômicas e históricas entre os praticantes. Nessa consideração entra o papel formativo da escola, em que, como o autor considera, toda cultura "se elabora nos termos de relações conflituais ou competitivas entre mais fortes e mais fracos, sem que nenhum espaço, pode instalar-se na certeza da neutralidade" (CERTEAU, 2004, p.86).

Silva (2009) discute esse espaço (escolar) que não é neutro e que há relações entre sujeitos praticantes de saberes/fazeres em diferentes espaços/tempos. O autor considera a plenitude, se em sua formação o ser humano concebe que é constituído a partir das "relações com a cultura, com os outros e com o ambiente". O autor ainda traz a concepção de que o "educando deve estar consciente de que a identidade de um povo e do próprio ser humano individualmente é construída de forma coletiva e constante. Que deve respeitar e valorizar os saberes contidos nas outras culturas" (SILVA, 2009, p.133).

O papel mais fundamental da escola, como local de formação e transformação é formar o ser humano, que tenha consciência "de que é possível aprender e trocar saberes ou conhecimentos com outros grupos. Essa troca não tem mão única, isto é, um povo que recebe, aprende e outro que ensina e traz o conhecimento" (SILVA, 2009, p.133). É uma mão dupla, fruto de um processo intersubjetivo que envolve a aceitação mútua, um ambiente de relações saudáveis que a escola e seus atores deve propiciar.

\section{Conclusão}

Considera-se, portanto, como fundamental aprofundar nas discussões epistemológicas e sociais, que permeiam o fenômeno educacional contemporâneo, em busca de soluções e melhoramentos, em prol de uma formação humana plena, que envolva o estudante como um todo; e que permita um ambiente favorável de tolerância e cultura de paz.

O processo educacional envolve a investigação sobre a própria realidade, partindo de valores e do cotidiano. Contemporaneamente, pode-se pensar o processo de ensino e aprendizagem, como um movimento único para o qual a metodologia utilizada interfere diretamente no processo, cujo currículo precisa partir do cotidiano escolar e permitir a transversalidade, multiculturalidade e socialização, para que as barreiras do individualismo e da cultura reproducionista sejam transpostos pela convicção do desenvolvimento do potencial humano. A reflexão crítica sobre a prática docente pode ser considerada uma ferramenta fundamental para a compreensão das demandas da contemporaneidade, pois os sujeitos possuem demandas, que necessitam de ações específicas e bem planejadas, livres de engessamento e repetições.

Os resultados do diagnóstico sobre bullying e violação dos direitos humanos e das atividades pedagógicas realizadas permitiram perceber a necessidade de uma atuação, que envolva os próprios jovens no processo pedagógico, de modo que o protagonismo jovem seja a mola de uma relação de motivação intrínseca e extrínseca de uma cultura de paz. 


\section{Referências}

BRASIL. Presidência da República. Casa Civil. Subchefia para Assuntos Jurídicos. Lei $n^{\circ}$ 9.394, de 20 de dezembro de 1996. Estabelece as diretrizes e bases da educação nacional. Brasília: DOU, 23.12.1996.

BRASIL. Presidência da República. Casa Civil. Subchefia para Assuntos Jurídicos. Lei $n^{\circ} 13.185$, de 6 de novembro de 2015. Institui o Programa de Combate à Intimidação Sistemática (Bullying). Brasília: DOU, 9.11.2015

BRASIL. Presidência da República. Casa Civil. Subchefia para Assuntos Jurídicos. Lei $n^{\circ} 13.663$, de 14 de maio de 2018. Altera o art. 12 da Lei $\mathrm{n}^{\circ}$ 9.394, de 20 de dezembro de 1996, para incluir a promoção de medidas de conscientização, de prevenção e de combate a todos os tipos de violência e a promoção da cultura de paz entre as incumbências dos estabelecimentos de ensino. Brasília: DOU, 15.5.2018.

CERTEAU. A invenção do cotidiano 1 : as artes de fazer. Petrópolis: Vozes, 2004.

CHALITA, G. Pedagogia da amizade - bullying: o sofrimento das vítimas e dos agressores. São Paulo: Gente, 2008.

COLL, C. et al. Os conteúdos da reforma: ensino e aprendizagem de conceitos, procedimentos e atitudes. Porto Alegre: Artes Médicas, 2000.

COLL, C.; EDWARDS, D. Ensino, aprendizagem e discurso em sala de aula: aproximações ao estudo do discurso educacional. Porto Alegre: Artes Médicas, 1998.
FANTE, C. Fenômeno Bullying: como prevenir a violência nas escolas e educar para a paz. Campinas: Verus, 2005.

GANDIN, D. A prática do planejamento participativo: na educação em outras instituições. Petrópolis: Vozes, 1994.

MARIN, A.J.; PIMENTA, S.G. Didática: teoria e pesquisa. Araraquara: Junqueira \& Marin, 2018.

OLIVEIRA, C. et al. Violência escolar no Brasil: desafios em curso na educação do século. In: CONGRESSO IBEROAMERICANO EM AVALIAÇÃO QUALITATIVA, 21., Salamanca. 2017. Anais... Salamanca, Espanha: CIAIQ, 2017.

SILVA, C.A. Educação, tolerância e direitos humanos: a importância do ensino de valores na escola. Porto Alegre: Sulina, 2009.

SILVA, T.T. Documentos de identidade: uma introdução às teorias do currículo. Belo Horizonte: Autentica, 2015.

SILVA, V.C.G. Violência escolar, bullying e violação de direitos humanos no cotidiano escolar. Cuiabá: Instituto Federal de Educação, Ciência e Tecnologia de Mato Grosso, 2019.

VÁSQUEZ, A.S. Filosofia da práxis. Rio de Janeiro: Paz e Terra, 1977.

ZABALA, A. A prática educativa: como ensinar. Porto Alegre: Artes Médicas, 1998.

ZABALA, A. Enfoque globalizador e Pensamento complexo. Porto Alegre: ARTMED, 2002. 